\title{
The University of Wisconsin-Stout Asynchronous Learning Network Case Study Options: Using Technology to Remove Learning Barriers
}

\author{
Joseph Holland \\ University of Wisconsin-Stout
}

\begin{abstract}
The University of Wisconsin-Stout Asynchronous Learning Network (ALN) project, funded by the Alfred P. Sloan Foundation, represents an effort to expand the boundaries of the traditional campus. The purpose of this project was to offer learning opportunities to both traditional students and industry professionals either on campus or away from the campus. The asynchronous method of delivery will allow learners to participate from any place at any time. This paper will review how the University of Wisconsin-Stout is using technology to remove learning barriers and provide students with learning options.

The focus of this paper is to provide a detailed explanation of the process the University of WisconsinStout used to implement an Asynchronous Learning Network. It will describe the history and background of the project, design and development issues, results and proposed next steps for this campus.
\end{abstract}

\section{INTRODUCTION}

\section{A. The Campus Mission}

The University of Wisconsin-Stout (UW-Stout), as a special mission institution, serves a unique role in the University of Wisconsin System. UW-Stout is characterized by a distinctive array of programs leading to professional careers focused on the needs of society. These programs are presented through an approach to learning that involves combining theory, practice, and experimentation. Extending this special mission into the future requires that instruction, research, and public service programs be adapted and modified as the needs of society change. Because of our special mission, many UW-Stout students participate in internships, co-ops, and work experiences during their degree program. The University was exploring ways to reach these students while they were away from campus and provide them with access to degree credits. In addition, the University works to serve other populations throughout the state, including business and industry. These populations also need access to learning activities ranging from credit generating courses through certification and professional development.

\section{B. The Project}

The UW-Stout has been involved in developing its Asynchronous Learning Network (ALN) since March 1995. Prior to that time, many faculty and staff at the University had been using an assortment of tools to provide students with access to courses from both on and off campus. March 1995 was the date when UW-Stout received an Alfred P. Sloan Foundation Officer's Grant to convert a course, Hospitality Industry Law and Liability, to asynchronous delivery. Hospitality Industry Law and Liability is a required course in the undergraduate degree program in Hotel, Restaurant and Tourism Management. It is offered in a traditional format on-campus during all academic semesters. The on-line version was first offered in the fall 1995 semester to a group of 12 students. The initial course was intended to serve students who were participating in co-op or internship experiences away from campus or students on-campus that could not attend the traditional courses because of schedule conflicts. Eight of the students were oncampus and four were away from campus. This included one person employed in the hospitality industry for more than 15 years who needed to complete the course as a prerequisite for a graduate degree program, three students out 
of state in co-op positions and three students who commuted to campus. The other student was on-campus but could not take the traditionally offered course because of a scheduling conflict.

In July 1996, the UW-Stout submitted and received a Sloan Foundation Trustee's grant. This grant built upon the Officer's grant and allowed us to create five additional courses and develop a certification program in Sanitation. This grant involved three faculty members, Dr. James J. Buergermeister, Dr. Randall S. Upchurch and Dr. Joseph W. Holland. They worked together as a team to design, test, and teach the additional courses. The Trustee's grant enabled us to develop a range of courses for the undergraduate degree program. These included: Introduction to Hospitality Management; Food, Beverage and Cost Control; Lodging Administration; Employee and Labor Relations in the Hospitality Industry; and Seminar in Hospitality and Tourism. These are required courses for the undergraduate degree program in Hotel, Restaurant and Tourism Management. This program requires 124 total undergraduate credits. We also had Jane Henderson working half time developing the Sanitation certification and assisting in technical development.

The previously developed Hospitality Industry Law and Liability course was published on-line in the fall 1995 semester with an enrollment of 20 students. Starting the spring 1997 semester, all five courses were on-line and Web accessible. The pilot of the Sanitation certification was provided to the Wisconsin Restaurant Association to test and evaluate. Enrollment in the on-line courses ranged from ten in the Seminar in Hospitality and Tourism course to 44 in the Hospitality Industry Law course. Approximately $80 \%$ of the students enrolled in the courses were on or near campus and the others were delivered throughout the United States.

\section{RATIONALE}

\section{A. Purpose}

The UW-Stout became interested in developing an ALN for a variety of reasons. The principal reason the grant team wanted to develop an ALN was to serve our students who were participating in co-op or internship activities. These students were asked to make a large commitment to complete one or more of these experiential activities. They would generally devote an academic semester to the experience. They received an invaluable experience, but would only earn between one to two academic credits on average. This meant that the students who chose to complete a coop or internship were doing so knowing that they were adding another semester to the time to complete their degree program. The grant team envisioned that by making courses available to students at a distance, many of the students in a co-op or internship could complete the experience and continue to complete course work towards their degree completion. The grant team also wanted to provide an option for students to complete their college program in the event they left campus prior to graduating. These were students working in the industry that needed to complete their undergraduate degree for career or personal reasons. They were often distant from the campus and had schedules that made it difficult to complete their degrees at a traditional campus. These two groups of students were the primary targets for asynchronous delivery.

UW-Stout works closely with business and industry and enjoys an excellent relationship with many of the major hospitality corporations. They indicated that they have a strong desire to provide educational opportunities for their associates. This ranges from degree credit courses through certification and professional development. Businesses are finding that it is becoming more and more expensive to send employees to a campus or other site for education or training. They are also being challenged with managing the training necessary in today's business environment. ALNs provide a way to meet these needs and demands in a cost-effective manner. Therefore, part of the focus of the grant looked into developing training and certification programs that could serve segments of the hospitality and tourism industry.

Closely related to the general needs of the hospitality and tourism industry was a project that UW-Stout was investigating with Door County, one of the state's busiest tourism destinations. Door County depended upon parttime student help to meet their needs. However, given the academic calendar, they faced a shortage of qualified help during the spring and fall. UW-Stout was working with business and government representatives from Door County 
to develop a way to provide students with educational opportunities during these seasons. The business professionals also indicated a strong desire for professional development and certification opportunities. Since Door County is located approximately 250 miles from the UW-Stout campus, this would involve transporting instructors to a facility on or near the Door Peninsula. An ALN would eliminate these geographic barriers and greatly reduce the cost of infrastructure to support their educational needs. The University saw this as another compelling reason to explore distance and asynchronous delivery.

The University also wanted to integrate with the K-12 system. Since the state of Wisconsin was strongly supporting a school-to-work initiative, we wanted to explore the possibility of offering introductory level classes to high school students on-line - providing them with an opportunity to earn college credits without traveling to a campus. It would also serve as a marketing tool to interest them in the professional degree programs offered at our university.

\section{B. Design Objectives}

A critical factor in the planning and implementation was educational quality and learning effectiveness. To assure that the students participating in the asynchronous courses were receiving at least the level of learning as students in traditional courses the grant team introduced a number of tools. Each of the classes offered asynchronously was also offered in the traditional mode. The grant team set up a system to administer pre-course and post-course tests to students enrolled in the traditional courses and asynchronous courses. The pre- and post-tests were designed to measure content knowledge coming into a course and upon completion of the course to determine the amount of learning that took place. The grant team had to design these tests so that the factors affecting the tests would be comparable. Therefore, we adopted a model of a power test. This was an objective test that covered all of the main content areas. There were 100 questions that had to be answered in a one-hour period. Additionally, the raw score would be adjusted for wrong answers to discourage students from random guessing. The scores from the pre-course test and the post-course test were not a factor in computing the students' course grades. This system provided us with a way to determine the learning that takes place and compare the traditional students' scores with the students in the asynchronous courses.

The data from these instruments allowed us to make a comparative study of the learning effectiveness of this small array of courses. Since the faculty involved in developing and teaching the asynchronous courses also taught or monitored the traditional courses, a valid comparison could be made. The project taught us that students could learn as well, or better, in an asynchronous environment under these conditions.

\section{BACKGROUND INFORMATION FOR THE COURSES}

\section{A. History of Asynchronous Learning on Campus}

Prior to commencing our first Sloan grant project, there were scattered attempts to engage in asynchronous learning at the University. Several faculty members were using E-mail, listservs and VAX Mail as an enhancement to traditional courses. Some had developed Internet maps to direct students to appropriate information. There was no concerted effort to explore and research asynchronous delivery at the University. Professor Holland had incorporated several asynchronous tools into his traditional class before the project. He used an application, Diploma IV by Brownstone Technology, to create self-assessment test banks that were distributed to students on a diskette. Most of the text documents for the course were also available on diskette, so students who had access to PC computers could use these materials at any time during the course. He also distributed PowerPoint presentations of lecture materials to students for use as a study aid or to facilitate learning for missed classes.

The grant team started our efforts from a very limited and naïve viewpoint. We engaged in converting traditional courses, designed in a pedagogical model for traditional delivery to undergraduate students. Based upon the available literature and discussions with other faculty engaged in asynchronous projects, we made some assumptions about our learners. The majority of students in our project were college-age traditional learners. They ranged in class standing from freshman through graduate students. A small number were non-traditional, professional, working adults. The grant team assumed that the non-traditional adults would perform best. We also assumed that those 
students with advanced computer skills would also do much better in the asynchronous classes. We did not build any prerequisites into course enrollment policies. The grant team wanted to learn if asynchronous course delivery could be an option for a large majority of students. Much of our research related to acquiring and using tools that would eliminate technical skills. That is why we settled on Lotus Notes and Lotus LearningSpace. Although Lotus Notes is a powerful and complex application, its design provided an environment where the technical skills were focused on establishing and maintaining the infrastructure and the learning could take place in a transparent environment.

\section{B. Enrollment in Asynchronous Courses}

Since our first offerings were limited to a maximum of 20 students, we provided an opportunity for a great amount of personal interaction between the instructors and the students. The grant team was exploring new territory and knew that we would have to devote some of the class time to building and supporting technical skills. Because of this individual attention, we experienced a very low attrition rate. In most cases, if a student were going to drop a class, it would occur early in the semester and was related to their difficulties with the technology. The grant team had learned from others that, although the goal was to create an asynchronous environment, we had to carefully structure the courses to encourage students to stay active and current.

The grant team developed a manual for students that guided them through the technical aspects of participating in the courses. We also provided a voluntary training session for students who enrolled in the asynchronous courses. We scheduled these training sessions at the end of the semester before they were scheduled to take an asynchronous course and at the very beginning of the course. More than $85 \%$ of students enrolled in the asynchronous courses attended these training sessions. The grant team also created a CD-ROM disc with ScreenCam videos directing students through each of the databases that comprised an asynchronous class. This CD-ROM disc also contained detailed instructions regarding installing a Lotus Notes client for students who wished to participate via a client instead of via the Web. The grant team wanted to provide as many tools and options to the students as possible to ensure successful completion of the course.

Following testing of content modules and discussion among the faculty teaching the asynchronous courses we set enrollment limits at 20 students. The grant team felt this would provide an opportunity for the anticipated interaction expected of asynchronous courses. This class size is smaller than many of our traditional classes, but we felt that since the instructors were learning as well as the students, we would have a better chance of success. Our experience demonstrated that this was a good decision. The asynchronous courses met enrollment maximums before the traditional classes filled in five of the six courses. The freshman level course had the smallest enrollment although the pool of potential students was larger. The senior level courses filled and we had requests beyond our enrollment caps.

\section{Learner Profiles}

One observation that the grant team made during the initial offering of the asynchronous courses was the general profile of the student. Among the on-campus traditional students, those students who were in the upper third of their class were more likely to enroll. This was a factor in our analysis of the effectiveness of asynchronous courses. The grant team found that the students enrolled in the asynchronous courses had a somewhat higher score on the precourse tests than the students in the traditional courses. However, we also found that the increase in scores for the post-test was greater than that for the traditional students. This supported a finding that learning was as effective in asynchronous courses as traditional courses, but was not in and of itself definitive proof. The on-going results of student progress in asynchronous courses have led to our current stage of development. We are engaged in a grant from the UW-system to create a concentration for our Graduate Hospitality and Tourism Program in Global Hospitality Management. This concentration is available only for asynchronous delivery. It is designed for professional adults with a minimum of three years of management experience in hospitality or tourism. The University is also committing funds to on-going development of undergraduate and graduate courses or programs for asynchronous delivery. Several initiatives have been created to encourage faculty and staff to pursue these efforts. 


\section{METHOD}

\section{A. Developing the Infrastructure}

Our efforts thus far represent only a small example of how to implement an asynchronous component for teaching and learning on campus. The project was limited to a single degree program, housed in a single department and championed by three faculty members. Therefore, it represents a scalable model, but by no means should it be viewed as a good model for development of large projects.

One of the first challenges facing us was the selection and development of the infrastructure to deliver our asynchronous courses. The grant team initially chose Lotus Notes based on the recommendations of previous Sloan Foundation grantees. We continued with Lotus Notes and LearningSpace when the opportunity to work together with Lotus Institute in the development and testing of a new application, Lotus LearningSpace, presented itself to us. However, that decision placed a lot of responsibility on the grant team because we were responsible for installing, developing, and maintaining the delivery environment ourselves. There was only limited support from the University because there were no personnel on staff with the skills and training to support Lotus Notes. The grant team was fortunate to have Lotus Institute as a partner at this point. We found and developed an undergraduate student with the ability to provide the technical support. Lotus Institute worked closely with this person to create our infrastructure for the successful delivery of courses. It is critical to have a stable environment for course delivery. Technical failures will lead to dissatisfaction and attrition among the students. We have had a stable infrastructure throughout the project due to the efforts of our system administrator and the support he received from personnel at Lotus Corporation.

The technical infrastructure was managed in-house. We also provided services to other projects from our site. We have a very basic Lotus Notes environment. Our domain name server is a Gateway 2000 Pentium 166Mhz machine with $32 \mathrm{M}$ RAM and a $3 \mathrm{G}$ hard drive. It is connected to the campus local area network with a $10 \mathrm{Mbps}$ Ethernet Network Interface Card. This server contains Lotus Notes and the name and address book for Lotus Notes. We have a second server that is reserved for course development and accessible only by faculty and students for development and testing purposes. It is a Gateway 2000 Pentium 200Mhz machine configured similar to the DNS machine. We have two multiprocessor servers for delivering courses. One is a Gateway 2000 with dual $400 \mathrm{Mhz}$ processors, $256 \mathrm{M}$ RAM and a four-drive RAID hard drive array with $36 \mathrm{G}$ of storage. The other is a Gateway 2000 with dual $350 \mathrm{Mhz}$ processors, 128M RAM and an 18G hard drive. Both of the multiprocessor machines have dual Ethernet Network Interface Cards. Finally, we have two servers for continued beta testing of emerging products. One is a Gateway 2000 machine with a $133 \mathrm{Mhz}$ processor, $32 \mathrm{M}$ RAM and a $2 \mathrm{G}$ hard drive the other is a Gateway 2000 machine with a 133Mhz processor, 64M RAM and a 4G hard drive.

The very first course was delivered using Lotus Notes in a client-server configuration. There was no Web-accessible version of LearningSpace at that time. Students on-campus could use one of two campus computer laboratories that contained PCs with Lotus Notes clients. They could also access from their personal computer if they wished, but were required to install a Lotus Notes client. Students away from campus had to have a Lotus Notes client on their computer.

\section{B. Course Design and Structure}

Starting in January 1996, Lotus LearningSpace became Web-accessible. Students now had a choice of accessing via the Internet or via a Lotus Notes client. The grant team encouraged access via the Internet because many of the students did not possess the technical skills to install and configure a Lotus Notes client. This placed an additional responsibility on the course designer because multimedia attachments needed to be created twice, once for client access and once for Web access.

All of our courses were structured to follow the traditional course schedule. Students could work ahead in courses, but had to have work completed by specific deadlines. There were also many activities designed for collaboration that required students to participate within defined time frames. This structure was chosen because our previous 
experience indicated that one factor in failure for the undergraduate student was poor time management. Students would try to complete a course just prior to the end of the semester and not leave themselves enough time to complete the required work satisfactorily. The structure was also chosen to encourage collaboration and interaction between and among students. The grant team developed a rigid schedule, created collaborative learning exercises and provided students with an opportunity to interact in the learning process. The original intent was to require students to use the threaded discussion features and interact with other students while learning. We found that forced or required discussion activities were not successful. Courses were more effective when redesigned to encourage and reward collaboration, but not to require discussion from all students.

Students have a variety of learning styles and there are many options available for asynchronous delivery. The grant team knew very little about what would be most successful, so we tried to incorporate as many options as possible into the courses. Much of the material was delivered through text files that were the easiest to develop and present for Web-delivered courses. Many students also responded that they preferred text summaries rather than PowerPoint presentations on-line. Some, however, indicated that the PowerPoint presentations were a valuable learning tool. We began experimenting with other multimedia programs and constantly sought student input to determine what forms of materials best supported learning.

We learned that variety was a component to successful design. Student learning styles are varied and they were best served when they had options available to support their learning. While a majority of students found simple text outlines to serve their on-line learning best, a significant percentage of students found that PowerPoint or Astound multimedia presentations were more useful for them. The grant team also began to explore using assessments as a learning tool. The Assessment Manager in LearningSpace was a weak application. We acquired a Web-based assessment tool, QuestionMark, to deliver our quizzes, tests, self-assessments, and surveys. This tool allowed us to create assessments that students could use to evaluate their own progress and also use as a learning tool.

\section{Assessment and Evaluation}

Assessing student performance is an important part of any course granting college credit. The grant team investigated a large range of options based on the course content. The courses included case studies, projects, written assignments, presentations, and research activities as a basis for evaluating student performance. Student input indicated that they wanted frequent quizzes and self-assessments. Since students were taking the courses without any direct supervision or proctoring, we designed these objective assessments to be taken open-book. All assessments were strictly timed. This was the only mechanism the grant team could develop to validate the assessments. Students had to possess knowledge of the subject matter to successfully complete the assessment within the time frame allowed. The program we chose to deliver our assessments would indicate the time an assessment was started, when it was completed, and the elapsed time. The program also provided a mechanism to randomly generate the quizzes and tests so that each student would have a unique test instrument. This would deter collaboration within activities where student interaction was not appropriate.

Most assessment involved subjective assignments. The instructors in the grant team agreed to include assessment activities that required a demonstration of both content and critical thinking skills. These included case studies and collaborative projects. We also required students to write reflective pieces relating to the content areas. These subjective activities were a more concrete way to demonstrate student performance given the asynchronous learning environment. Review of subjective assignments in relation to student contributions in the CourseRoom discussions enabled us to closely monitor student progress. We also engaged students in peer review. Students would submit an assignment for grading and the instructor would route that assignment to other students for review and comment. This encouraged students to collaborate more, since they learned to provide constructive criticism to their peers. The quality of writing increased also. The student's written contributions to the class would be available for everyone to review and the students began taking more time to proof read materials they submitted. 


\section{Learning Tools}

Our basic approach to course design was to provide students with learning options. We explored and used a number of technologies to provide the necessary learning tools. We also had to choose applications that could be distributed with a viewer or player so those students could use the programs. The grant team found the most popular office application packages contained many valuable tools. In addition to text files, we could create and distribute electronic presentations, spreadsheet simulations, short video clips and related types of files. However, many of these files were too large for efficient distribution over the Internet. We used a hybrid approach to solve this problem. Each student could receive a CD-ROM disc containing the larger media files, the necessary players, viewers and browsers, and their Lotus Notes client. We included text files for instructions and Lotus ScreenCam videos to assist students with using the technology chosen for the delivery environment.

This was necessary because we were offering the classes completely asynchronously. There was no prerequisite knowledge of Lotus Notes, Lotus LearningSpace, or other applications required. The grant team did offer voluntary, one-hour training sessions to assist students who were taking the course(s) for the first time. The training sessions were successful to a point. Training, prior experience, and attitude toward learning technology were key variables. The sessions were scheduled at the end of the academic semester prior to the course being taken and at the beginning of the academic semester when the course was offered. Students who were going to be distant from campus could attend the session before they left campus. Students who wanted to get an early start on the course could also attend the earlier session. Students on or near campus would usually schedule themselves to take the session at the beginning of the semester. Each session would provide an overview of Lotus Notes and Lotus LearningSpace, a demonstration of simple Microsoft Windows operations and an introduction to navigating the Internet. The students responded that they found these sessions to be very useful. It also provided an opportunity for students with limited computer skills to drop the course if they decided they were not prepared to learn in this type of environment. Many could then enroll in a traditional offering of the course.

\section{E. Organization and Evolution}

The grant team adopted a faculty/developer model from the onset of our project. The faculty member teaching the course would also create the course and all of the activities and files for the course. We had a small team working together who were able to share their skills. We also had a technical-support person to work with the team who had a wide range of multimedia skills. We also involved students in testing and refining the courses. Student employees and volunteers would review the course, check entries, activities and links, and recommend improvements and changes to the instructors. The grant team also participated in each other's courses and offered suggestions. This process allowed us to review effective designs and adopt a common approach for the entire array of courses. One of the important factors that the students identified was consistency of form and function. Courses with a consistent "look and feel" are preferred and provide an effective transition for students taking multiple courses. They reported that too many differences in the appearance of course components or use of supporting applications detracted from learning and often left them confused and frustrated. Many had participated in other courses with asynchronous components and they did not want to have to learn a new set of computer skills simply to be able to participate in courses.

Technical support was very important to the success of our projects. None of the faculty on the development team had skills necessary to maintain a stable learning environment and effectively use the tools that were available. The grant team hired a half-time system administrator. We found an undergraduate student in the Telecommunications program who accepted this position as a co-op experience for his degree. He had superior skills and was essential to the success of the project. Peter Tratechaud installed, maintained, and managed the Lotus Notes/Domino servers. He also administered the other servers used for supporting applications. We have a Windows NT server that hosts QuestionMark Perception, our assessment program. We have another server to host Real Audio and Real Video applications for streaming media. He set up and maintains an FTP site where students can obtain browsers, viewers, players, and other software. In addition to the equipment and software duties, he also administers user identification files, and password distribution. He is available to answer students' technical questions through a LearningSpace help link provided on the course Website. Tratechaud works closely with developers regarding technical aspects of 
the delivery platform and supporting applications. He is also the only one authorized, under the supervision of a faculty administrator, to create or publish courses.

\section{F. Funding}

The original development was made possible by two Alfred P. Sloan Foundation grants. The first grant, an Officer's grant, was in the amount of $\$ 29,681$. This grant allowed the UW-Stout to release Professor Holland for 40 days to develop the Hospitality Industry Law and Liability course for asynchronous delivery. Professor Buergermeister was released for 13 days to conduct research on Door County to determine the feasibility of providing asynchronous delivery of courses and professional development. In addition, Professors Buergermeister and Holland were responsible for developing training programs for students taking the asynchronous courses and faculty interested in developing asynchronous courses.

The second Sloan Foundation Trustee's grant was for $\$ 289,676$. The UW-Stout contributed approximately $\$ 75,000$ towards programming costs and absorbed a portion of the normal indirect costs associated with a grant. This project was much more elaborate. It involved release time for the faculty development team, support for a half time system administrator, support for a half-time academic staff support person, miscellaneous student help, and related expenses over a one-year period. This funding supported the development of five existing courses for asynchronous delivery and one certification program, the presentation and teaching of the courses, and expanded training of faculty and staff. The grant team also conducted research into the needs and desires of hospitality industry businesses regarding credit offerings and professional development opportunities. They researched delivery options, integration of supporting applications, and support tools. They also evaluated the learning effectiveness, student needs, learning outcomes, and effective design issues relating to asynchronous teaching and learning. During this period, members of the grant team engaged in dissemination of results through professional presentations throughout the world.

\section{G. Next Steps}

The Department of Hospitality and Tourism is now building on those results with the development of a concentration for the Hospitality and Tourism Master's Degree Program in Global Hospitality Management. The UW-System, through a Central Investment Fund grant in the amount of $\$ 344,000$, funds this effort. The Global Hospitality Management concentration is a collaborative effort among several campuses to provide an opportunity for industry professionals to obtain an advanced degree through our ALN. The curriculum is being developed and will be taught cooperatively. Many of the courses will be team taught by members of the faculty from the partner institutions. We have engaged business and industry advisors to assist in designing and evaluating the curriculum. This concentration is designed to serve professionals with a minimum of three years of management experience currently working in the hospitality and tourism industries. The degree-granting partners are the UW-Stout and Oxford Brookes University in the United Kingdom. Core educational partners include the UW-Whitewater, Nottingham Trent University in the United Kingdom, and Paderborn University in Germany. Core business partners include Marriott Corporation and IBM.

The UW-Stout will begin delivering the program this fall with an initial enrollment of 15 to 20 students. There is a resident activity scheduled for late August that will bring the participants together for a three-day period to build team and collaborative skills, conduct training regarding the technology and provide a opportunity for interpersonal exchange among the students and faculty. The curriculum is designed to build on already developed professional skills and provide the students with an opportunity to apply theory to their current work experiences. The concentration requires successful completion of 36 graduate credits. There is a core of 27 credits in required courses, which includes a thesis or professional project. The students have the option to select the additional nine credits from courses offered by approved partner institutions. 


\section{RESULTS}

The grant team has been very satisfied with our experiences in ALN. The development and delivery of the asynchronous courses were subjected to rigorous evaluation. Since this method of teaching is so new, many things that can be taken for granted in traditional courses must be addressed and validated. We created a series of evaluations and surveys that were used to monitor and enhance the learning experience for our students.

\section{A. Success Factors and Barriers}

At the beginning of the project the grant team developed a survey to determine student expectations in the asynchronous courses. We also gathered demographic information to determine a "profile" for successful students. Throughout the course, we encouraged and obtained input from students regarding their impressions of useful learning activities and tools. We met as a group and discussed and analyzed what we observed in the courses we were teaching. Especially important to us were factors that encouraged interaction and collaboration, timely communication, and evidence of content mastery. The grant team was very pleased by the general acceptance of this method of learning by the students. They indicated that this environment allowed them to control the learning and made them more effective. We also learned that this method of learning was not for every student, no matter how well intentioned.

Although many students easily adapted to the technology, technical problems were the major barrier. If the student could not access the material due to technical problems, they became anxious and upset. The very flexibility that asynchronous learning provided became a harsh master. If the student could not participate when she or he was ready because the server or network was not working properly, he or she had lost a valuable learning opportunity. Students needed immediate and accurate responses to problems. The instructor had to commit to frequent involvement and respond to questions in a timely manner.

Collaborate learning activities were also a major challenge. Although we recognized the value of interaction between and among the students and tried to design activities to support that interaction, many students did not know how to collaborate. The grant team attempted to require and reward collaboration as graded activities, but true evaluation of learning through these exercises was difficult to assess. Often, required discussions or projects became a conflict between quantity and quality. We observed that students who took a second course became "leaders" in the course for other students and would provide tips on how to maximize the experience. They would share with other students ways to use self-assessments and supporting materials to perform better in the class. A majority of students combined the asynchronous collaborative activities with synchronous meetings when it was possible. The students taught us how to design courses with materials and activities that would serve a large variety of learning styles and needs.

The grant team was very encouraged when more than $75 \%$ of the students who were eligible to enroll in another asynchronous course chose to do so. We continue to see a very high rate of enrollment in other asynchronous courses. Students have also begun to demand asynchronous components to traditional classes and the department is engaged in developing a method to provide this in all of our undergraduate classes.

\section{B. Synchronous and Asynchronous Comparisons}

We were also very satisfied with the comparisons of the pre-course and post-course tests between the traditional and asynchronous courses. Even though our designs were primitive, the correlation between learning effectiveness was essentially the same in both types of courses. Students demonstrated that they learned well when they understood what was expected and sufficient resources were provided. They often returned to early discussions and re-opened them to more thoroughly discuss previous materials. One activity that was designed for the Seminar in Hospitality and Tourism class that received a very high evaluation from the students was the visiting expert. Professor Upchurch arranged for the authors of various case studies used in the class to make themselves available in the asynchronous course to discuss the issues and their interpretations. This provided an opportunity for the on-line students that we could not afford the traditional students and brought most students to a higher level of understanding and analysis. 
The grant team also observed that students tended to complete the asynchronous courses at approximately the same rate as traditional courses. We used the class rosters established after the drop-add period as a comparison, since course enrollments tend to be very fluid at the beginning of the semester. Most students who were intimidated by the technology or course expectations would drop the course early. We are experiencing a higher initial drop rate now than at the beginning of the project. It is difficult to follow up with students who drop a class, but our efforts have provided us with some explanations. Several students who were contacted regarding their decision to drop a course and take the traditional course indicated that their access to a computer or the Internet from home or another location away from campus was the biggest factor. If they could not participate in the course asynchronously, it did not have value to them. Another factor is course expectations. Some students perceive that the on-line courses are easier. When they enroll and find that the expectations are the same as for traditional courses they choose to take the traditional courses.

\section{Providing Options to Remove Learning Barriers}

In conclusion, the grant team has found that learning effectiveness can be obtained in asynchronous courses by using technology to provide the students with options. Asynchronous learning effectiveness is no different that synchronous learning effectiveness when it comes to creating barriers. However, asynchronous courses do provide us with a mechanism to remove many of those barriers. We can create our learning environment to permit students to access from any place at any time. We can create content that provides the learning tools to accommodate many different learning styles. We can tap into the vast resources of the Internet to provide our students with simulations, animations, and applications that enable effective learning to take place. We can create rich, reusable, and dynamic resources that can be used to engage the learner in adding to and developing the content knowledge base. ALNs provide us with an opportunity to develop learning communities where even subtle barriers such as age, race, gender, or appearance can be eliminated. Finally, we can use technology to create a learning environment where other physical barriers such as sight or hearing can be overcome and students can engage in learning that satisfies their needs and desire.

\section{ABOUT THE AUTHOR}

Joseph Holland, J.D. is Professor, Department of Hospitality \& Tourism University of the University of Wisconsin-Stout. Professor Holland has been involved in Asynchronous Learning Networks for several years. He is presently involved in a project that involves developing a degree concentration in Global Hospitality Management that will be offered exclusively on-line. This master's degree concentration is being developed collaboratively with several universities internationally. Professor Holland currently serves as a national and international consultant regarding asynchronous teaching and learning.

Contact: Department of Hospitality and Tourism, HE441, University of Wisconsin-Stout, Menomonie, Wisconsin 54751; Telephone: 715-232-1995; Fax: 715-232-2588; E-mail: hollandj@uwstout.edu; URL: http://dht.uwstout.edu. 


\title{
The University of Wisconsin-Stout Asynchronous Learning Network Case Study Options: Using Technology to Remove Learning Barriers
}

\author{
Joseph Holland
}

\section{Discussant: Anthony Picciano, Hunter College}

Joseph Holland presents a case study of the implementation and development of an ALN at the University of Wisconsin-Stout during the years 1995 to the present. Funded by a grant received from the Alfred P. Sloan Foundation, in fall 1995, the University of Wisconsin-Stout offered its first asynchronous learning course, Hospitality Industry Law and Liability, in its undergraduate program in Hotel, Restaurant, and Tourism Management. By fall 1999, the University was embarking on offering entire degree programs on-line. Several elements of this case study are typical of the implementation and development of ALN in higher education in the 1990s.

The student population at the University of Wisconsin-Stout can be characterized as non-traditional with interests and goals related to clearly defined careers. The academic courses chosen for the initial ALN implementation were offered in specific professional degree and certificate programs rather than in broad-based liberal arts programs. These academic programs and concentrations require extensive internships, cooperative working experiences, and other off-campus activities. Providing an ALN vehicle for these students allowing them to take courses at their convenience and to reduce some of the travel time between home, school, and business has had significant appeal at the University of Wisconsin-Stout.

The faculty who were part of the initial ALN deployment were pioneers or champions who had to devote extensive time and effort to launch the first on-line courses. Significant release time was provided by grant funds in order to accomplish this. The faculty also had to work with a dynamically evolving software technology that was changing every few months. Beta versions of course management software packages were experimented with and tested as part of the ALN implementation. The case study clearly demonstrates that faculty engaging in ALN development in the 1990s had to devote many hours to experimenting with both software and pedagogy.

Grant and other special funding arrangements were necessary for the initial and to some degree for the continued support for the ALN development. The Alfred P. Sloan Foundation provided two grants, an initial program officer's grant of $\$ 29,681$, and a trustee's grant of $\$ 289,676$. While the University of Wisconsin-Stout contributed approximately $\$ 75,000$ to the earlier ALN efforts, the most recent initiative is being funded by the University of Wisconsin-System Central Investment Fund for $\$ 344,000$. The case study demonstrates the entrepreneurial spirit of the faculty and other participants while also demonstrating that the University has not yet mainstreamed ALN into its routine funding and resource allocation processes.

An important aspect of this case study was to provide insight into student experiences with ALN. Formal data were not presented and the case study could have provided basic demographic, i.e., gender, ethnicity, age, information on the student participants. Regardless, a good deal of information derived from the author's experiences and observations were presented and are worth reviewing.

First, to be successful, ALN technology need not be overly sophisticated. The basic features of course management software packages work well for establishing the essential instructional communications tools. The case study identifies the major barriers for students to complete successfully ALN courses were technological. Internet access 
problems were a significant reason why students dropped out of ALN courses. This confirms the importance of student help and support facilities, especially with regard to technical assistance.

Second, the author identified several pedagogical techniques that led to successful student experiences with ALN. Students have different learning styles and good instructional design requires some variety of activities. Collaborative learning and multimedia were specifically mentioned as pedagogical techniques that were successful. To insure vibrant interaction among students, enrollment limits of 20 students per course were established. The case study also makes a point of mentioning that writing was an important part of most ALN courses and that student writing improved as the course progressed.

Third, in terms of overall student satisfaction and performance, the case study indicates that ALN is not for all students. By the same token, once students have had a successful experience with ALN, they are likely to re-enroll in additional ALN courses. Overall student performance was on a par with students in traditional courses.

The case study raises several important issues at the University of Wisconsin-Stout where ALN is in the process of scaling up from its experimental stages. Funding for ALN still appears to be a special consideration and derived from sources outside the normal budget allocation processes. Planning appears to be limited and is based essentially on the spirit and dedication of the early faculty pioneers. Administrative processes are minimally mentioned with regard to planning and budgeting for ALN even as more and more faculty are becoming involved. Policy issues such intellectual property, faculty workload, and special compensation may have to be considered for ALN to scale up successfully at the University. Technical support for faculty was sparse and until recently consisted of a part-time system administrator who was a talented undergraduate at the University. These are not necessarily serious issues but areas that the case study might have explored further.

This is a lucid case study that provides many insights into the learning issues associated with the initial experimentation and development of ALN course by a cadre of faculty pioneers. It will be interesting to follow its evolution as planning, policy, funding, and other issues arise.

\section{ABOUT THE DISCUSSANT}

Anthony G. Picciano is a Professor in the graduate program in Education Administration and Supervision. His teaching specializations are organization theory, research methods, contemporary issues in education, and instructional technology. He has also taught in the graduate and undergraduate programs in elementary and secondary education.

Contact: School of Education, Department of Curriculum and Teaching, Hunter College of the City University of New York, 695 Park Avenue, New York, New York 10021; Telephone: 212-772-4694; Fax: 212-650-3959; E-mail: antho13926@aol.com. 